Article

\title{
Sustainable and Resilient Supply Chain Network Design under Disruption Risks
}

\author{
Sonia Irshad Mari, Young Hae Lee ${ }^{\dagger} * *$ and Muhammad Saad Memon ${ }^{\dagger}$ \\ Industrial and Management Engineering Department, Hanyang University, 55 Hanyangdeahak-ro, \\ Sangnok-gu, Ansan, Kyoenggi-do 426-791, Korea; E-Mails: sonia@hanyang.ac.kr (S.I.M.); \\ msmemon@hanyang.ac.kr (M.S.M.) \\ $\dagger$ These authors contributed equally to this work. \\ * Author to whom correspondence should be addressed; E-Mail: yhlee@hanyang.ac.kr; \\ Tel.: +82-31-400-5262.
}

External editor: Marc A. Rosen

Received: 22 July 2014; in revised form: 17 September 2014 / Accepted: 19 September 2014 / Published: 29 September 2014

\begin{abstract}
Sustainable supply chain network design is a rich area for academic research that is still in its infancy and has potential to affect supply chain performance. Increasing regulations for carbon and waste management are forcing firms to consider their supply chains from ecological and social objectives, but in reality, however, facilities and the links connecting them are disrupted from time to time, due to poor weather, natural or manmade disasters or a combination of any other factors. Supply chain systems drop their sustainability objectives while coping with these unexpected disruptions. Hence, the new challenges for supply chain managers are to design an efficient and effective supply chain network that will be resilient enough to bounce back from any disruption and that also should have sufficient vigilance to offer same sustainability under a disruption state. This paper focuses on ecological sustainability, because an environmental focus in a supply chain system is more important and also links with other pillars of sustainability, as the products need to be produced, packed and transported in an ethical way, which should not harm social balance and the environment. Owing to importance of the considered issue, this paper attempts to introduce a network optimization model for a sustainable and resilient supply chain network by incorporating (1) sustainability via carbon emissions and embodied carbon footprints and (2) resilience by incorporating location-specific risks. The proposed goal programming (GP)
\end{abstract}


model optimizes the total cost, while considering the resilience and sustainability of the supply chain network.

Keywords: resilient supply chain; sustainable supply chain; disruption risks; green supply chain

\section{Introduction and Literature Review}

Today supply chain management is emerging in a new dimension by having the sustainability as its primary focus, but in reality, however, facilities and the links connecting them are disrupted from time to time due to poor weather, natural or manmade disasters or a combination of any other factors. At the same time, corporations are accepting broader responsibility for the social and environmental impacts of their supply chains. However, a supply chain system drops its sustainability objectives while coping with those unexpected disruptions. Therefore, supply chain managers are now trying to develop a trade-off between supply chain disruptions and a sustainable system. Resilience is a new approach to the design of supply chains and business processes. It is derived from the study of resilience in biological systems, which have a variety of mechanisms for sensing and responding to disturbances or threats. Whereas sustainability was only considered previously as a means to manage the logistics of the supply chain, the modern supply chain networks consider sustainability as their primary focus [1]. The current supply chains already realize the importance of making more sustainable networks and try to concentrate more on environmental and social factors in order to make more transparent supply chain networks.

Research and practical applications of sustainable supply chain management (SSCM) have been growing steadily in recent times [2]. Elkington [3] described three pillars of sustainability, namely economy, ecology and society. This paper focuses more on ecological sustainability, because an environmental focus in supply chain systems is more important and also links with other pillars, as the products need to be produced, packed and transported in an ethical way, which should not harm social balance and the environment. Many authors considered sustainable procurement to ensure minimum embodied carbon footprints (e.g., [4-8]) and sustainable transportation (e.g., [9-12]) in the supply chain context. However, the focus of ecological sustainability has now moved from local optimization to the entire supply chain [13]. There are very few articles that have considered the sustainability factor with respect to the entire supply chain (e.g., [2,14-16]), which means that all activities, from procurement of raw materials to distribution of finished goods, should consider sustainable factors.

In the socio-economic literature, there is much evidence that shows the connections and relationships between resiliency and sustainability, like Derissen, et al. [17], who discusses the relationship between sustainability and resilience in ecological-economic systems. They consider sustainability as a normative concept, whereas resilience is a descriptive concept, and with the help of a simple dynamic model, they try to explain the relationship between sustainability and resilience. Rose [18] in his paper discusses the role of sustainability and resilience in the face of natural disasters and also discusses the relationship between them. The author also describes the different types of resilience and concluded that sustainability helps a great deal with improvement after a severe natural disaster, but it cannot be possible without having adaptive and inherent resilience associated with 
disaster recovery. Turner [19] considers that resilience and vulnerability are two parallel and coalescing approaches that belong to sustainability science, and the author also explains the similarities and differences across the two concerned areas with respect to sustainability science practices. Lebel, et al. [20] illustrates that resilience is one of the critical factors for sustainability, and in order to pursue efficient and effective sustainable development, there is a need to strengthen the ability of societies to manage resilience. Perrings [21] explains how the relationship between sustainability and resilience effects the economics of development and also claims that, "A development strategy is not sustainable if it is not resilient". Cutter [22] illustrates a framework in his paper in which he considered resilience as a bridge between disaster risk management and sustainable communities. According to him, it is very important to consider resilience as a major element that helps in achieving sustainable development and further stated that considering resilience is necessary for both sustainable development and disaster risk management.

In accordance with the importance of the above literature, this paper gives considerations to both resilience and sustainability in the context of supply chain management. According to Rose [18], extreme disruptions could badly effect the environment, which disrupts the major activities of supply chains. The major barrier in developing a sustainable supply chain network is the uncertainty associated with supply chain activities. Therefore, a sustainable supply chain should be resilient and flexible enough to cope with uncertain disruptions [23]. This requires one to build sustainable supply chains that are simultaneously resilient, agile and lean to cope with uncertain disruptions, such as natural or manmade disasters [24]. Disruption of supply chain networks leads to supply uncertainty and is important for sustainable supply chain performance, because firms try to find alternate solutions to cope with disrupted supply and might lose sustainability. There is an enormous amount of literature existing on supply chain resilience (e.g., [25-30]), which shows the importance of this research in the supply chain area; however, to the best of the authors' knowledge, no single study is available in the literature that jointly discusses the resilience and sustainability issue in the supply chain context.

In order to design a sustainable supply chain network that is simultaneously resilient enough to cope with uncertain events, we used a resilience metric, known as the expected disruption cost (EDC), which is based on expected losses incurred due to network failures. According to Shukla, et al. [31], "The EDC is defined in terms of loss of opportunity cost incurred due to not meeting demand on time after a disruption has occurred". This paper proposes the weighted goal programming (WGP) model, aiming to balance the level of ecological sustainability via carbon emissions and embodied carbon footprints and resilience by incorporating location-specific risks, such as natural and/or manmade disasters. The main objective of the proposed supply chain model is to ensure that the supply chain network is sustainable, as well as resilient enough to cope with unexpected disruption risks, because the set of partners in the supply chain network have different degrees of implementation of sustainable supply chain practices and abilities to cope with disruptions risks [32].

\section{Mathematical Model}

In this section, the mathematical model for a sustainable and resilient supply chain network will be discussed in detail. The research proposes a framework to design a sustainable and resilient supply chain as shown in Figure 1. 
Figure 1. Sustainable and resilient supply chain network framework.

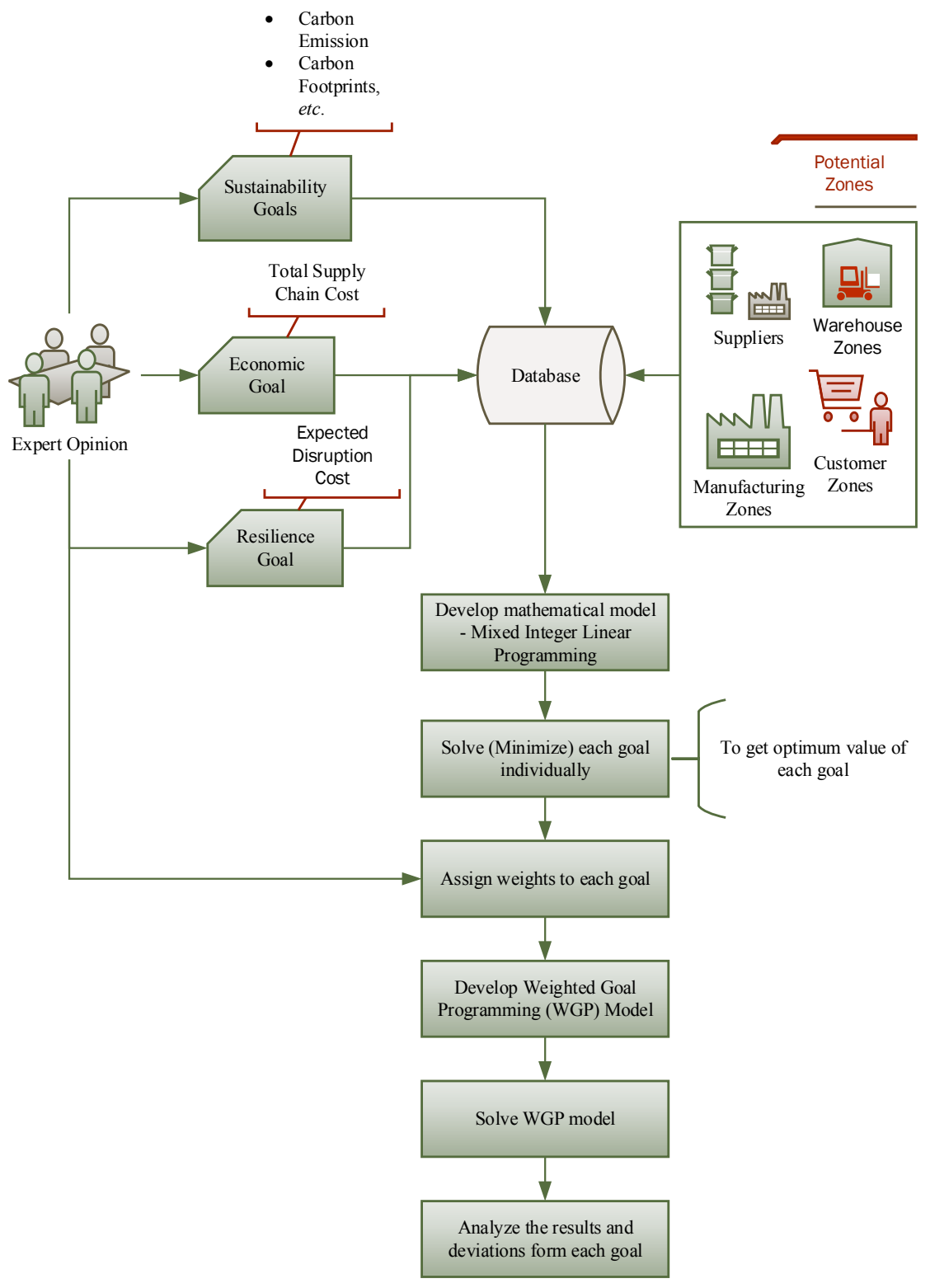

We have used the weighted goal programming (WGP) approach to construct the model, because WGP is generally used to deal with multi-objective optimization problems. This paper deals with different conflicting objectives, and WGP is a suitable approach for obtaining a compromise solution [33]. This paper considers a supply chain network consisting of a set of suppliers $(L)$ from which various raw materials are purchased by a set of manufacturing zones $(J)$, where the product is manufactured and distributed to various warehouse zones $(K)$, from which the product is dispatched to customer zones $(I)$. This study considers three different types of trucks $(T)$ that are used to deliver products between each supply chain node. The proposed model attempts to find a trades-off between the total costs associated with the supply chain network, the disruption costs due to the vulnerability of the manufacturing and/or warehouse zones, the embodied carbon foot print of the materials procured from different suppliers and the total carbon emissions due to transportation and manufacturing. The model has been validated for a garment manufacturing supply chain as a case example. Notations and assumptions of the model are as follows: 


\subsection{Sets}

$i$, set of customer zones

$j$, set of manufacturing zones

$k$, set of warehouse zones

$l$, set of suppliers

$t$, set of different types of trucks

$p$, set of periods

$$
\begin{aligned}
& i=\{i \mid 1,2, \ldots, I\} \\
& j=\{j \mid 1,2, \ldots, J\} \\
& k=\{k \mid 1,2, \ldots, K\} \\
& l=\{l \mid 1,2, \ldots, L\} \\
& t=\{t \mid 1,2, \ldots, T\} \\
& p=\{t \mid 1,2, \ldots, P\}
\end{aligned}
$$

\subsection{Parameters}

$d_{i p} \quad$ Annual demand at customer zone $i$ in period $p$

$M_{j} \quad$ Cost of installing a manufacturing unit in zone $j$

$W_{k} \quad$ Cost of installing a warehouse in zone $k$

$U P C_{l p} \quad$ Purchase cost of material from supplier $l$ (\$/unit) in period $p$

$E C F_{l p} \quad$ Embodied carbon footprints of the material purchased from supplier $l$ in period $p$

$T_{C S M}$ litp Transportation cost from supplier $l$ to manufacturing zone $j$ using truck $t$ (\$/unit) in period $p$

$T C M W_{j k t p}$ Transportation cost from manufacturing zone $j$ to warehouse zone $k$ using truck $t$ (\$/unit) in period $p$

$T C W C_{\text {kitp }}$ Transportation cost from warehouse zone $k$ to customer zone $i$ using truck $t$ (\$/unit) in period $p$

$H C S M_{l j p} \quad$ Handling cost from supplier $l$ to manufacturing unit in zone $j$ (\$/unit) in period $p$

$H C M W_{j k p} \quad$ Handling cost from manufacturing zone $j$ to warehouse in zone $k$ (\$/unit) in period $p$

$H C W C_{k i p}$ Handling cost from warehouse in zone $k$ to customer zone $i$ (\$/unit) in period $p$

$C_{E S M} \quad$ Carbon emission by truck $t$ from supplier $l$ to manufacturing zone $j$ (kg/unit) in period $p$

$C E M W_{j k t p}$ Carbon emission by truck $t$ from manufacturing zone $j$ to warehouse zone $k$ (kg/unit) in period $p$

$C E W C_{k i t p} \quad$ Carbon emission by truck $t$ from warehouse zone $k$ to customer zone $i(\mathrm{~kg} / \mathrm{unit})$ in period $p$

$M C_{j p} \quad$ Manufacturing cost at zone $j$ (\$/unit) in period $p$

$C E_{j} \quad$ Carbon emission by manufacturing unit in zone $j$ (kg/unit)

$C S_{l p} \quad$ Capacity of supplier $l$ in period $p$

$C M_{j p} \quad$ Capacity of manufacturing unit in zone $j$ in period $p$

$C T_{t p} \quad$ Capacity of truck $t$ in period $p$

$C W_{k p} \quad$ Capacity of inventory in warehouse $k$ in period $p$

$P M_{p} \quad$ Profit margin on each unit in period $p$

$s d_{l p} \quad$ Supplier's disruption probability in period $p$

$m d_{j p} \quad$ Manufacturing zone's disruption probability in period $p$

$w d_{k p} \quad$ Warehouse zone's disruption probability in period $p$

\subsection{Decision Variables}

$x_{k}= \begin{cases}1 & \text { If a warehouse in zone } k \text { is open } 1 \text {, otherwise } 0\end{cases}$

$y_{j}= \begin{cases}1 & \text { If a manufacturing unit in zone } j \text { is open } 1 \text {, otherwise } 0\end{cases}$ 
$T Q S M_{l j p} \quad$ Transportation quantity from supplier $l$ to manufacturing zone $j$ using truck $t$ in period $p$

$T Q M W_{j k t p}$ Transportation quantity from manufacturing zone $j$ to warehouse zone $k$ using truck $t$ in period $p$

$T Q W C_{k i t p} \quad$ Transportation quantity from warehouse zone $k$ to customer zone $i$ using truck $t$ in period $p$

\subsection{Deviational Variables}

$d_{a}^{+}, d_{a}^{+} \quad$ Under and over achievement from total supply chain cost goal

$d_{b}, d_{b}^{+} \quad$ Under and over achievement from carbon emission goal

$d_{c}, d_{c}^{+} \quad$ Under and over achievement from embodied carbon footprint goal

$d_{d}, d_{d}^{+} \quad$ Under and over achievement from disruption cost goal as a measure of resilience

\subsection{Model}

The objective of the proposed GP model is to minimize the deviations from the goals. The objective function in Equation (1) minimizes the weighted deviation around the goals.

$$
\text { Minimize } \beta_{1} d_{a}^{+}+\beta_{2} d_{b}^{+}+\beta_{3} d_{c}^{+}+\beta_{4} d_{d}^{+}
$$

where $d_{a}^{+}, d_{b}^{+}, d_{c}^{+}$and $d_{d}^{+}$represent the deviational variables of cost, carbon emission, embodied carbon footprints and resilient supply chain goals, respectively, and $\beta_{1}, \beta_{2}, \beta_{3}$ and $\beta_{4}$ are the corresponding weights of the above objective deviations. It is important to recognize in Equation (1) that deviations of goals are measured in different units, i.e., $\$$ and $\mathrm{kg}$; therefore, we cannot sum them directly due to the phenomenon of incommensurability. Percentage normalization is used in the proposed model to standardize the unit in the objective function. Percentage normalization is carried out by dividing the deviations with their corresponding target levels. Thus, all deviations are measured in the same units, as shown in Equation (2).

$$
\text { Minimize } \beta_{1} \frac{d_{a}^{+}}{\text {Goal (A) Target }}+\beta_{2} \frac{d_{b}^{+}}{\text {Goal (B) Target }}+\beta_{3} \frac{d_{c}^{+}}{\text {Goal (C)Target }}+\beta_{4} \frac{d_{d}^{+}}{\text {Goal (D) Target }}
$$

Various costs associated with the supply chain are calculated in Equations (3)-(7). The purchase costs of materials from various suppliers are computed in Equation (3). Production costs in different manufacturing zones are calculated in Equation (4). Equation (5) computes the transportation costs of the whole supply chain. Handling costs are shown in Equation (6). Installation costs of manufacturing units and warehouses are computed in Equation (7). Finally, the total supply chain cost goal can be computed as in Equation (8).

$$
\begin{gathered}
\text { Purchase cost }=\sum_{l} \sum_{p} U P C_{l p} \sum_{j} \sum_{t} T Q S M_{l j t p} \\
\text { Production cost }=\sum_{j} \sum_{p} M C_{j p} \sum_{k} \sum_{t} T Q M W_{j k t p} \\
\text { Transportation cost }=\begin{array}{l}
\sum_{l} \sum_{j} \sum_{t} \sum_{p} T Q S M_{l j t p} T C S M_{l j t p}+\sum_{j} \sum_{k} \sum_{t} \sum_{p} T Q M W_{j k t p} T C M W_{j k t p} \\
+\sum_{k} \sum_{i} \sum_{t} \sum_{p} T Q W C_{k i t p} T C W C_{k i t p}
\end{array}
\end{gathered}
$$




$$
\begin{gathered}
\text { Handling cost }=\begin{array}{l}
\sum_{l} \sum_{j} \sum_{p} H C S M_{l j p} \sum_{t} T Q S M_{l j t p}+\sum_{j} \sum_{k} \sum_{p} H C M W_{j k p} \sum_{t} T Q M W_{j k p} \\
+\sum_{k} \sum_{i} \sum_{p} H C W C_{k i p} \sum_{t} T Q W C_{k i t p}
\end{array} \\
\text { Installation cost }=\sum_{j} M_{j} y_{j}+\sum_{k} W_{k} x_{k}
\end{gathered}
$$

Total supply chain cost goal $(\mathrm{A})=$ Purchase cost + Production cost + Transportation cost $t^{r}$

$$
+ \text { Handling cost }+ \text { Installation cost }+d_{a}^{-}-d_{a}^{+}
$$

Various carbon emissions in the supply chain are computed in Equations (9)-(12). Equation (9) computes the total carbon emissions occurring during the transportation of the materials from suppliers to manufacturing zones. Equation (10) computes the total carbon emissions during the transport of finished products form manufacturing zones to warehouse zones. Total carbon emissions for transporting the products from warehouses to customer zones is computed in Equation (11). Equation (12) computes the carbon emissions during manufacturing. Finally, the total carbon emission goal can be shown by Equation (13).

Carbon emission during transport of material

from suppliers to manufacturing zones $=\sum_{l} \sum_{j} \sum_{t} \sum_{p} T Q S M_{l j p} C E S M_{l j t p}$

Carbon emission during transport of products

from manufacturing zones to warehouse zones $=\sum_{j} \sum_{k} \sum_{t} \sum_{p} T Q M W_{j k t p} \mathfrak{C} E M W_{j k t p}$

Carbon emission during transport of products

from warehouse zones to customer zones $=\sum_{k} \sum_{i} \sum_{t} \sum_{p} T Q W C_{k i t p} C E W C_{k i t p}$

Carbon emission in manufacturing $=\sum_{j} C E_{j} \sum_{k} \sum_{t} \sum_{p} T Q M W_{j k t p}$

Total carbon emission goal $(\mathrm{B})=$

Carbon emission during transport of material from supplier to manufacturing zones

+ Carbon emission during transport of products from manufacturing zones to warehouse zones

+ Carbon emission during transport of products from warehouse zones to customer zones

+ Carbon emission in manufacturing $+\mathrm{d}_{b}^{-}-d_{b}^{+}$

In order to achieve the total sustainability of the supply chain, it is very important to minimize the embodied carbon footprint of the procured material. It is one of the important factors in the supplier selection decision. For example, procurement of a high carbon embodied footprint raw material lowers the sustainability objectives of the manufacturer, even if it is present in a highly green zone, and they may face legal restrictions, because of being in a green zone. Equation (14) computes the total embodied carbon footprint goal of the procured material.

$$
\text { Embodied carbon footprint goal }(\mathrm{C})=\sum_{l} \sum_{p} E C F_{l p} \sum_{j} \sum_{t} T Q S M_{l j t p}+d_{c}^{-}-d_{c}^{+}
$$

One of the main objectives of this research is to consider the supply chain resilience. There may be many metrics for supply chain resilience; however, expected disruption cost (EDC) is a major metric. 
We use EDC as a metric for designing a resilient supply chain network, for example if any supplier is vulnerable to disruptions, then the manufacturer may go for another supplier without considering the sustainability factor in order to minimize the risk of being out of stock with respect to the disruption risk. Furthermore, sustainability and resiliency will again be affected if the manufacturing unit and/or warehouse are located in zones that are vulnerable, due to any reason, such as earthquakes, tsunamis or manmade disasters. Although the probability of disruption is hard to quantify [31], Lim et al. [34] found that even the probability of disruption is hard to quantify, but underestimating the likelihood of a disruption is more dangerous than overestimating the likelihood. Chopra and Sodhi [35] showed that less than a $2 \%$ increment in the total cost may be incurred even with a $50 \%$ error in estimating the disruption probability. This shows that one cannot completely ignore the likelihood of disruptions while designing the supply chain, and rough estimations of disruption risks are sufficient. This paper used an international disaster database to estimate the disruption probability, as shown by $[31,36]$. The goal (D) tries to minimize the expected disruption cost, which means increasing the supply chain resilience. The proposed model tries to ensure that all of the partners in the supply chain should have resilient behavior, that is, representing the partners' abilities to cope with unexpected disruption risks. Equation (15) estimates the expected disruption costs that are due to the vulnerability of suppliers, manufacturing zones and warehouse zones.

$$
\text { Disruption cost goal (D) }=\left(\begin{array}{l}
\sum_{l} \sum_{p} T Q S M_{l j p} s d_{l p}+\sum_{j} \sum_{p} T Q M W_{j k t p} m d_{j p}+ \\
\sum_{k} \sum_{p} T Q W C_{k i t p} w d_{k p}
\end{array}\right) P M_{p}+d_{d}^{-}-d_{d}^{+}
$$

The model constraints are described in Equations (17)-(33). Constraints (16) and (17) ensure that products can only be shipped from the manufacturing unit in zone $j$ if it exists in that zone. Similarly, Constraints (18) and (19) ensure that products can only be shipped from a warehouse in zone $k$ if it is open in that zone; where $m$ is very large number.

$$
\begin{gathered}
T Q S M_{l j t p} \leq m \times y_{j} \\
T Q M W_{j k t p} \leq m \times y_{j} \\
T Q M W_{j k t p} \leq m \times x_{k} \\
T Q W C_{k i t p} \leq m \times x_{k}
\end{gathered}
$$

Constraints (20)-(22) guarantee that transportation quantities between supplier, manufacturer and warehouse will not be more than their respective capacities.

$$
\begin{gathered}
\sum_{j} \sum_{t} T Q S M_{l i t p} \leq C S_{l p} \\
\sum_{k} \sum_{t} T Q M W_{j k t p} \leq C M_{j p} \\
\sum_{i} \sum_{t} T Q W C_{k i t p} \leq C W_{k p}
\end{gathered}
$$


Constraints (23)-(25) ensure that transportation quantities between supplier, manufacturer and warehouse will not exceed the total capacity of truck.

$$
\begin{gathered}
\sum_{l} \sum_{j} T Q S M_{l i t p} \leq C T_{t p} \\
\sum_{j} \sum_{k} T Q M W_{j k t p} \leq C T_{t p} \\
\sum_{k} \sum_{i} T Q W C_{k i t p} \leq C T_{t p}
\end{gathered}
$$

Constraint (26) balances the input and output of the material in a manufacturing unit. The amount of incoming material from suppliers to manufacturer is equal to the amount of outgoing material from manufacturer to warehouse. The inventory and the condition of being out of sock is not considered in this case. Similarly, Constraint (27) balances the input and output of finished products in warehouse units. The incoming products from manufacturing units are equal to outgoing units to various customer zones.

$$
\begin{aligned}
& \sum_{l} \sum_{t} T Q S M_{l j t p}-\sum_{j} \sum_{t} T Q M W_{j k t p}=0 \\
& \sum_{j} \sum_{t} T Q M W_{j k t p}-\sum_{k} \sum_{t} T Q W C_{k i t p}=0
\end{aligned}
$$

Constraint (28) confirms that the amount of products coming from manufacturing units to a warehouse in zone $k$ must be less than its inventory capacity.

$$
\sum_{j} \sum_{t} T Q M W_{j k t p} \leq C W_{k p}
$$

Constraint (29) certifies that the amount of products manufactured in zone $j$ unit must be less than its capacity.

$$
T Q M W_{j k t p} \leq C M_{j p}
$$

Constraint (30) promises that the amount of products transported from warehouses to customer zone $i$ will satisfy its demand.

$$
\sum_{k} \sum_{t} T Q W C_{k i t p}-d_{i p}=0
$$

Constraints (31)-(33) impose positive and binary restrictions on all of the corresponding decision variables, respectively.

$$
\begin{gathered}
T Q S M_{l j t p}, T Q M W_{j k t p}, T Q W C_{k i t p} \geq 0 \text { and integer } \quad \forall l, j, k, t, p \\
d_{a}^{+}, d_{b}^{+}, d_{c}^{+}, d_{d}^{+}, d_{a}^{-}, d_{b}^{-}, d_{c}^{-}, d_{d}^{-} \geq 0 \\
x_{k}, y_{j} \in\{0,1\} \quad \forall k, j
\end{gathered}
$$

\section{Case Example}

A garment manufacturing firm is chosen to show the applicability of the proposed model. The garment manufacturing company is based in Pakistan, having three manufacturing plants in different 
zones. The company procured different materials from local and foreign suppliers. The company operates various retail stores and warehouses around the country to meet the demand of customers. For experimental purposes, we take a single product (trousers) having a weight of $340 \mathrm{gm}$ and $i=5, j=3$, $k=4, l=3, t=3, p=3$. Various goals are set, such as: the cost goal (A) $=\$ 1,983,192.00$, the carbon emission goal $(B)=19,666.04 \mathrm{~kg}$, the embodied carbon footprints goal $(C)=199,590.00 \mathrm{~kg}$ and the disruption cost goal $(\mathrm{D})=\$ 303,712.50$. These goal values are found by separately minimizing each goal using linear programming. Manmade and natural disaster factors are used to quantify the probability of the disruption of each zone in the proposed model. To calculate the probability of disruption, historic data are used from the South Asia Terrorism Portal (SATP) and National Disaster Management Authority of Pakistan (NDMA) to calculate the manmade and the natural disasters during 2012-2013, as shown in Table 1. The disruption probability of suppliers, manufacturing zones and warehouse zones depends on the region in which they are located. Three cases are solved by varying the weight of Goals A, B, C and D, respectively, to analyze the results. Tables 2-16 show the required parameters used for solving the proposed model.

Table 1. Disruption probability of each region.

\begin{tabular}{ccccc}
\hline Region No. & Region Name & No. of Manmade Disasters & No. of Natural Disasters & Probability \\
\hline 1 & Faisalabad & 00 & 01 & 0.003 \\
2 & Hyderabad & 03 & 00 & 0.010 \\
3 & Karachi & 86 & 02 & 0.280 \\
4 & Lahore & 05 & 04 & 0.029 \\
5 & Peshawar & 53 & 01 & 0.172 \\
6 & Quetta & 54 & 01 & 0.175 \\
7 & Rawalpindi & 04 & 00 & 0.013 \\
\hline
\end{tabular}

Table 2. Cost (\$/unit) of the raw material purchased from different suppliers at different periods.

\begin{tabular}{ccccc}
\hline & & \multicolumn{3}{c}{ Period } \\
\cline { 3 - 5 } & & $\mathbf{1}$ & $\mathbf{2}$ & $\mathbf{3}$ \\
\hline \multirow{3}{*}{ Supplier } & $\mathbf{1}$ & 4.119 & 4.609 & 4.392 \\
& $\mathbf{2}$ & 4.016 & 4.588 & 5.654 \\
& $\mathbf{3}$ & 4.911 & 5.016 & 5.516 \\
\hline
\end{tabular}

Table 3. Embodied carbon footprints $(\mathrm{kg})$ of raw material purchased from suppliers at different periods.

\begin{tabular}{llccc}
\hline & & \multicolumn{3}{c}{ Period } \\
\cline { 3 - 5 } & & $\mathbf{1}$ & $\mathbf{2}$ & $\mathbf{3}$ \\
\hline \multirow{3}{*}{ Supplier } & $\mathbf{1}$ & 2.4 & 2.7 & 2.8 \\
& $\mathbf{2}$ & 1.9 & 2.0 & 2.2 \\
& $\mathbf{3}$ & 1.5 & 1.8 & 2.1 \\
\hline
\end{tabular}


Table 4. Raw material handling costs (\$/unit) from suppliers to manufacturing zones at different periods.

\begin{tabular}{lcccccccccc}
\hline \multirow{2}{*}{ Period } & \multicolumn{3}{c}{ Supplier 1 } & \multicolumn{3}{c}{ Supplier 2 } & \multicolumn{3}{c}{ Supplier 3 } \\
\cline { 2 - 11 } & 1 & $\mathbf{1}$ & $\mathbf{2}$ & $\mathbf{3}$ & $\mathbf{1}$ & $\mathbf{2}$ & $\mathbf{3}$ & $\mathbf{1}$ & $\mathbf{2}$ & $\mathbf{3}$ \\
\hline \multirow{3}{*}{ Manufacturing Zones } & 2 & 0.020 & 0.010 & 0.020 & 0.015 & 0.020 & 0.010 & 0.015 & 0.013 & 0.011 \\
& 3 & 0.009 & 0.008 & 0.010 & 0.008 & 0.009 & 0.020 & 0.011 & 0.012 & 0.013 \\
\hline
\end{tabular}

Table 5. Finished product handling costs from manufacturing zones to warehouse zones (\$/unit) at different periods.

\begin{tabular}{ccccccccccc}
\hline \multirow{2}{*}{ Period } & \multicolumn{4}{c}{ Manufacturing Zone 1 } & \multicolumn{4}{c}{ Manufacturing Zone 2 } & \multicolumn{4}{c}{ Manufacturing Zone 3 } \\
\cline { 2 - 10 } & 1 & $\mathbf{1}$ & $\mathbf{2}$ & $\mathbf{3}$ & $\mathbf{1}$ & $\mathbf{2}$ & $\mathbf{3}$ & $\mathbf{1}$ & $\mathbf{2}$ & $\mathbf{3}$ \\
\hline \multirow{3}{*}{ Warehouse Zones } & 2 & 0.015 & 0.011 & 0.014 & 0.013 & 0.014 & 0.016 & 0.012 & 0.019 & 0.013 \\
& 3 & 0.020 & 0.015 & 0.020 & 0.008 & 0.012 & 0.020 & 0.013 & 0.020 & 0.015 \\
& 4 & 0.015 & 0.011 & 0.014 & 0.013 & 0.014 & 0.016 & 0.012 & 0.019 & 0.013 \\
\hline
\end{tabular}

Table 6. Finished product handling costs from warehouse zones to customer zones (\$/unit) at different periods.

\begin{tabular}{cccccccccccccc}
\hline \multirow{2}{*}{ Period } & \multicolumn{4}{c}{ Warehouse Zone 1 } & \multicolumn{3}{c}{ Warehouse Zone 2 } & \multicolumn{3}{c}{ Warehouse Zone 3 } & \multicolumn{3}{c}{ Warehouse Zone 4 } \\
\cline { 2 - 13 } & & $\mathbf{1}$ & $\mathbf{2}$ & $\mathbf{3}$ & $\mathbf{1}$ & $\mathbf{2}$ & $\mathbf{3}$ & $\mathbf{1}$ & $\mathbf{2}$ & $\mathbf{3}$ & $\mathbf{1}$ & $\mathbf{2}$ & $\mathbf{3}$ \\
\hline \multirow{3}{*}{ Customer } & 1 & 0.010 & 0.015 & 0.020 & 0.020 & 0.016 & 0.020 & 0.014 & 0.012 & 0.011 & 0.012 & 0.011 & 0.011 \\
Zones & 2 & 0.020 & 0.011 & 0.015 & 0.015 & 0.012 & 0.013 & 0.012 & 0.019 & 0.015 & 0.015 & 0.016 & 0.013 \\
& 3 & 0.008 & 0.009 & 0.011 & 0.011 & 0.015 & 0.020 & 0.015 & 0.016 & 0.013 & 0.012 & 0.019 & 0.013 \\
& 4 & 0.010 & 0.011 & 0.011 & 0.02 & 0.015 & 0.02 & 0.025 & 0.028 & 0.025 & 0.028 & 0.029 & 0.030 \\
& 5 & 0.020 & 0.011 & 0.015 & 0.015 & 0.012 & 0.013 & 0.012 & 0.019 & 0.015 & 0.015 & 0.016 & 0.013 \\
\hline
\end{tabular}

Table 7. Raw material transportation costs $\left(\times \frac{1}{10^{5}}\right)$ from suppliers to manufacturing zones by different trucks at different periods.

\begin{tabular}{|c|c|c|c|c|c|c|c|c|c|c|c|c|}
\hline & \multirow{2}{*}{\multicolumn{2}{|c|}{ Period }} & & \multicolumn{3}{|c|}{ Truck Type 1} & \multicolumn{3}{|c|}{ Truck Type 2} & \multicolumn{3}{|c|}{ Truck Type 3} \\
\hline & & & & 1 & 2 & 3 & 1 & 2 & 3 & 1 & 2 & 3 \\
\hline \multirow{9}{*}{ Supplier } & \multirow{3}{*}{1} & \multirow{3}{*}{$\begin{array}{c}\text { Manufacturing } \\
\text { Zone }\end{array}$} & 1 & 6.57 & 6.57 & 6.57 & 2.55 & 2.55 & 2.55 & 1.91 & 1.91 & 1.91 \\
\hline & & & 2 & 47.4 & 47.4 & 47.4 & 18.4 & 18.4 & 18.4 & 13.8 & 13.8 & 13.8 \\
\hline & & & 3 & 340.0 & 340.0 & 340.0 & 132.2 & 132.2 & 132.2 & 99.1 & 99.1 & 99.1 \\
\hline & \multirow{3}{*}{2} & \multirow{3}{*}{$\begin{array}{c}\text { Manufacturing } \\
\text { Zone }\end{array}$} & 1 & 47.4 & 47.4 & 47.4 & 18.4 & 18.4 & 18.4 & 13.8 & 13.8 & 13.8 \\
\hline & & & 2 & 2.85 & 2.85 & 2.85 & 1.11 & 1.11 & 1.11 & 8.33 & 8.33 & 8.33 \\
\hline & & & 3 & 300.0 & 300.0 & 300.0 & 116.6 & 116.6 & 116.6 & 87.5 & 87.5 & 87.5 \\
\hline & \multirow{3}{*}{3} & \multirow{3}{*}{$\begin{array}{c}\text { Manufacturing } \\
\text { Zone }\end{array}$} & 1 & 340.0 & 340.0 & 340.0 & 132.2 & 132.2 & 132.2 & 99.1 & 99.1 & 99.1 \\
\hline & & & 2 & 300.0 & 300.0 & 300.0 & 116.6 & 116.6 & 116.6 & 87.5 & 87.5 & 87.5 \\
\hline & & & 3 & 2.85 & 2.85 & 2.85 & 1.11 & 1.11 & 1.11 & 8.33 & 8.33 & 8.33 \\
\hline
\end{tabular}


Table 8. Finished product transportation costs $\left(\times \frac{1}{10^{5}}\right)$ from manufacturing zones to warehouse zones by different trucks at different periods.

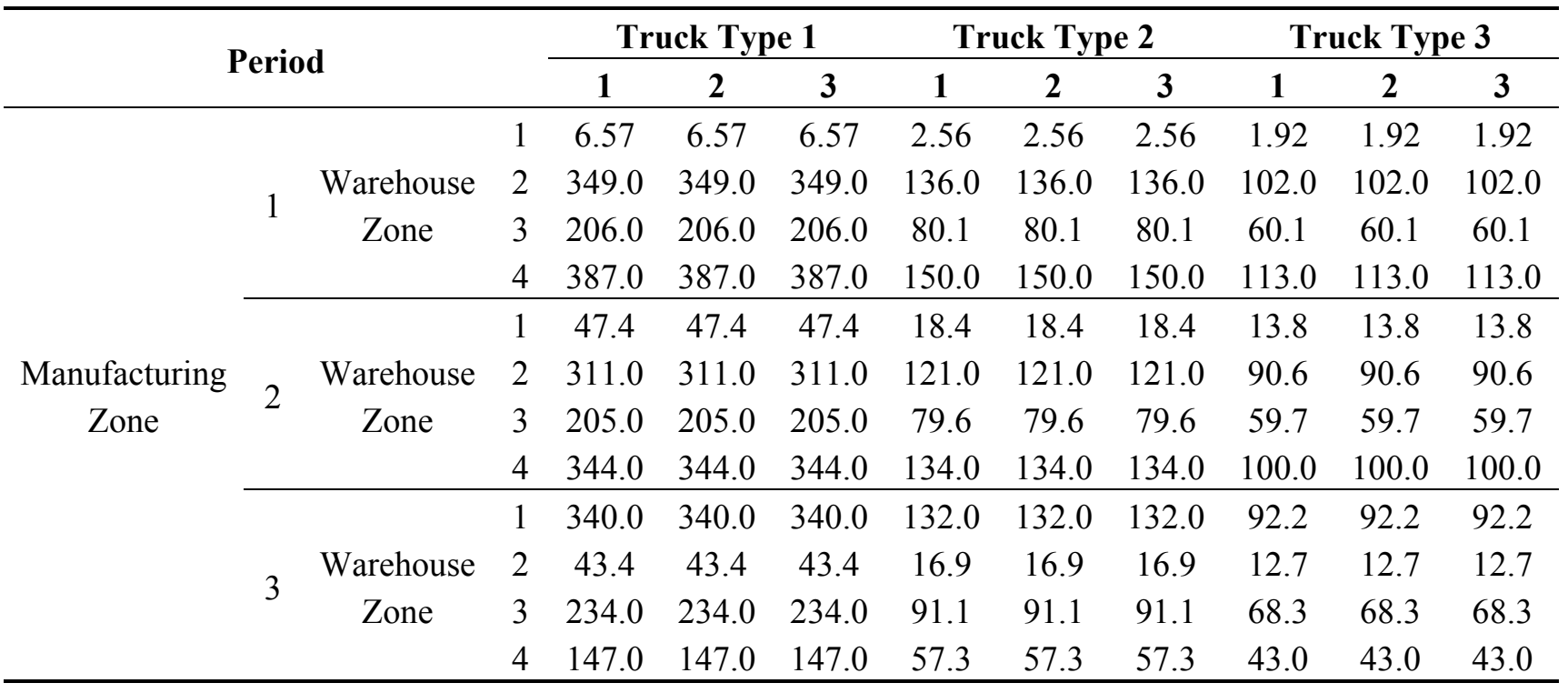

Table 9. Finished product transportation costs $\left(\times \frac{1}{10^{5}}\right)$ from warehouse zones to customer zones by different trucks at different periods.

\begin{tabular}{|c|c|c|c|c|c|c|c|c|c|c|c|c|}
\hline & \multirow{2}{*}{\multicolumn{2}{|c|}{ Period }} & & \multicolumn{3}{|c|}{ Truck Type 1} & \multicolumn{3}{|c|}{ Truck Type 2} & \multicolumn{3}{|c|}{ Truck Type 3} \\
\hline & & & & 1 & 2 & 3 & 1 & 2 & 3 & 1 & 2 & 3 \\
\hline \multirow{20}{*}{$\begin{array}{c}\text { Warehouse } \\
\text { Zone }\end{array}$} & \multirow{5}{*}{1} & \multirow{5}{*}{$\begin{array}{c}\text { Customer } \\
\text { Zone }\end{array}$} & 1 & 6.57 & 6.57 & 6.57 & 2.56 & 2.56 & 2.56 & 1.92 & 1.92 & 1.92 \\
\hline & & & 2 & 350.0 & 350.0 & 350.0 & 136.0 & 136.0 & 136.0 & 102.0 & 102.0 & 102.0 \\
\hline & & & 3 & 206.0 & 206.0 & 206.0 & 80.1 & 80.1 & 80.1 & 60.1 & 60.1 & 60.1 \\
\hline & & & 4 & 411.0 & 411.0 & 411.0 & 160.0 & 160.0 & 160.0 & 120.0 & 120.0 & 120.0 \\
\hline & & & 5 & 387.0 & 387.0 & 387.0 & 150.0 & 150.0 & 150.0 & 113.0 & 113.0 & 113.0 \\
\hline & \multirow{5}{*}{2} & \multirow{5}{*}{$\begin{array}{c}\text { Customer } \\
\text { Zone }\end{array}$} & 1 & 350.0 & 350.0 & 350.0 & 136.0 & 136.0 & 136.0 & 102.0 & 102.0 & 102.0 \\
\hline & & & 2 & 2.86 & 2.86 & 2.86 & 1.11 & 1.11 & 1.11 & 0.83 & 0.83 & 0.83 \\
\hline & & & 3 & 266.0 & 266.0 & 266.0 & 103.0 & 103.0 & 103.0 & 77.5 & 77.5 & 77.5 \\
\hline & & & 4 & 105.0 & 105.0 & 105.0 & 40.7 & 40.7 & 40.7 & 30.5 & 30.5 & 30.5 \\
\hline & & & 5 & 135.0 & 135.0 & 135.0 & 52.3 & 52.3 & 52.3 & 39.3 & 39.3 & 39.3 \\
\hline & \multirow{5}{*}{3} & \multirow{5}{*}{$\begin{array}{c}\text { Customer } \\
\text { Zone }\end{array}$} & 1 & 206.0 & 206.0 & 206.0 & 80.1 & 80.1 & 80.1 & 60.1 & 60.1 & 60.1 \\
\hline & & & 2 & 266.0 & 266.0 & 266.0 & 103.0 & 103.0 & 103.0 & 77.5 & 77.5 & 77.5 \\
\hline & & & 3 & 2.86 & 2.86 & 2.86 & 1.11 & 1.11 & 1.11 & 8.33 & 8.33 & 8.33 \\
\hline & & & 4 & 257.0 & 257.0 & 257.0 & 100.0 & 100.0 & 100.0 & 75.0 & 75.0 & 75.0 \\
\hline & & & 5 & 241.0 & 241.0 & 241.0 & 93.8 & 93.8 & 93.8 & 70.3 & 70.3 & 70.3 \\
\hline & \multirow{5}{*}{4} & \multirow{5}{*}{$\begin{array}{c}\text { Customer } \\
\text { Zone }\end{array}$} & 1 & 387.0 & 387.0 & 387.0 & 150.0 & 150.0 & 150.0 & 113.0 & 113.0 & 113.0 \\
\hline & & & 2 & 135.0 & 135.0 & 135.0 & 52.3 & 52.3 & 52.3 & 39.3 & 39.3 & 39.3 \\
\hline & & & 3 & 241.0 & 241.0 & 241.0 & 93.8 & 93.8 & 93.8 & 70.3 & 70.3 & 70.3 \\
\hline & & & 4 & 48.3 & 48.3 & 48.3 & 18.8 & 18.8 & 18.8 & 14.1 & 14.1 & 14.1 \\
\hline & & & 5 & 2.86 & 2.86 & 2.86 & 1.11 & 1.11 & 1.11 & 8.33 & 8.33 & 8.33 \\
\hline
\end{tabular}


Table 10. Carbon emissions $\left(\times \frac{1}{10^{3}} \mathrm{~kg}\right)$ for raw material transportation from suppliers to manufacturing zones by different trucks at different periods.

\begin{tabular}{|c|c|c|c|c|c|c|c|c|c|c|c|c|}
\hline & & \multirow{2}{*}{ Period } & & \multicolumn{3}{|c|}{ Truck Type 1} & \multicolumn{3}{|c|}{ Truck Type 2} & \multicolumn{3}{|c|}{ Truck Type 3} \\
\hline & & & & 1 & 2 & 3 & 1 & 2 & 3 & 1 & 2 & 3 \\
\hline \multirow{9}{*}{ Supplier } & \multirow{3}{*}{1} & \multirow{3}{*}{$\begin{array}{c}\text { Manufacturing } \\
\text { Zone }\end{array}$} & 1 & 0.93 & 0.93 & 0.93 & 0.85 & 0.85 & 0.85 & 0.87 & 0.87 & 0.87 \\
\hline & & & 2 & 6.74 & 6.74 & 6.74 & 6.12 & 6.12 & 6.12 & 6.27 & 6.27 & 6.27 \\
\hline & & & 3 & 48.3 & 48.3 & 48.3 & 43.8 & 43.8 & 43.8 & 44.9 & 44.9 & 44.9 \\
\hline & \multirow{3}{*}{2} & \multirow{3}{*}{$\begin{array}{l}\text { Manufacturing } \\
\text { Zone }\end{array}$} & 1 & 6.74 & 6.74 & 6.74 & 6.12 & 6.12 & 6.12 & 6.27 & 6.27 & 6.27 \\
\hline & & & 2 & 0.40 & 0.40 & 0.40 & 0.36 & 0.36 & 0.36 & 0.37 & 0.37 & 0.37 \\
\hline & & & 3 & 42.6 & 42.6 & 42.6 & 38.7 & 38.7 & 38.7 & 39.7 & 39.7 & 39.7 \\
\hline & \multirow{3}{*}{3} & \multirow{3}{*}{$\begin{array}{c}\text { Manufacturing } \\
\text { Zone }\end{array}$} & 1 & 48.3 & 48.3 & 48.3 & 43.9 & 43.9 & 43.9 & 45.0 & 45.0 & 45.0 \\
\hline & & & 2 & 42.6 & 42.6 & 42.6 & 38.7 & 38.7 & 38.7 & 39.7 & 39.7 & 39.7 \\
\hline & & & 3 & 0.40 & 0.40 & 0.40 & 0.36 & 0.36 & 0.36 & 0.37 & 0.37 & 0.37 \\
\hline
\end{tabular}

Table 11. Carbon emissions $\left(\times \frac{1}{10^{3}} \mathrm{~kg}\right)$ for finished product transportation from manufacturing zones to warehouse zones by different trucks at different periods.

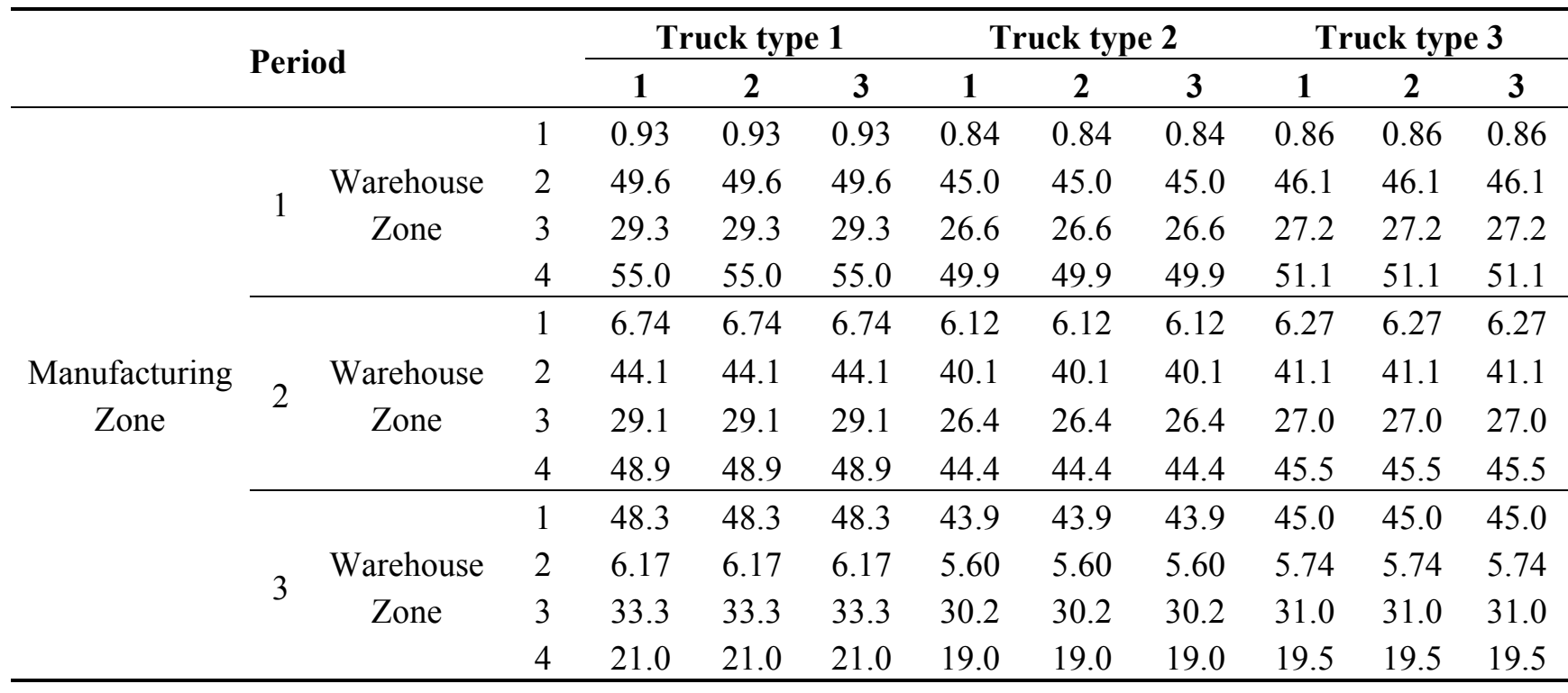

Table 12. Emissions $\left(\times \frac{1}{10^{3}} \mathrm{~kg}\right)$ for finished product transportation from warehouse zones to customer zones by different trucks at different periods.

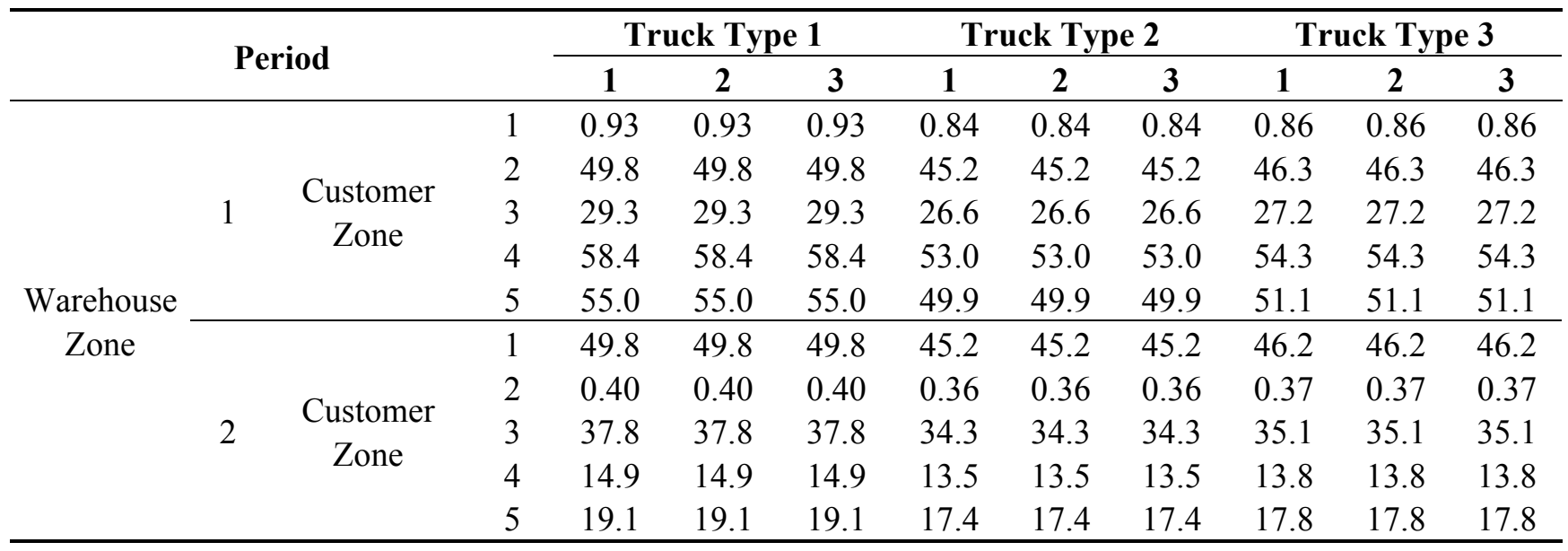


Table 12. Cont.

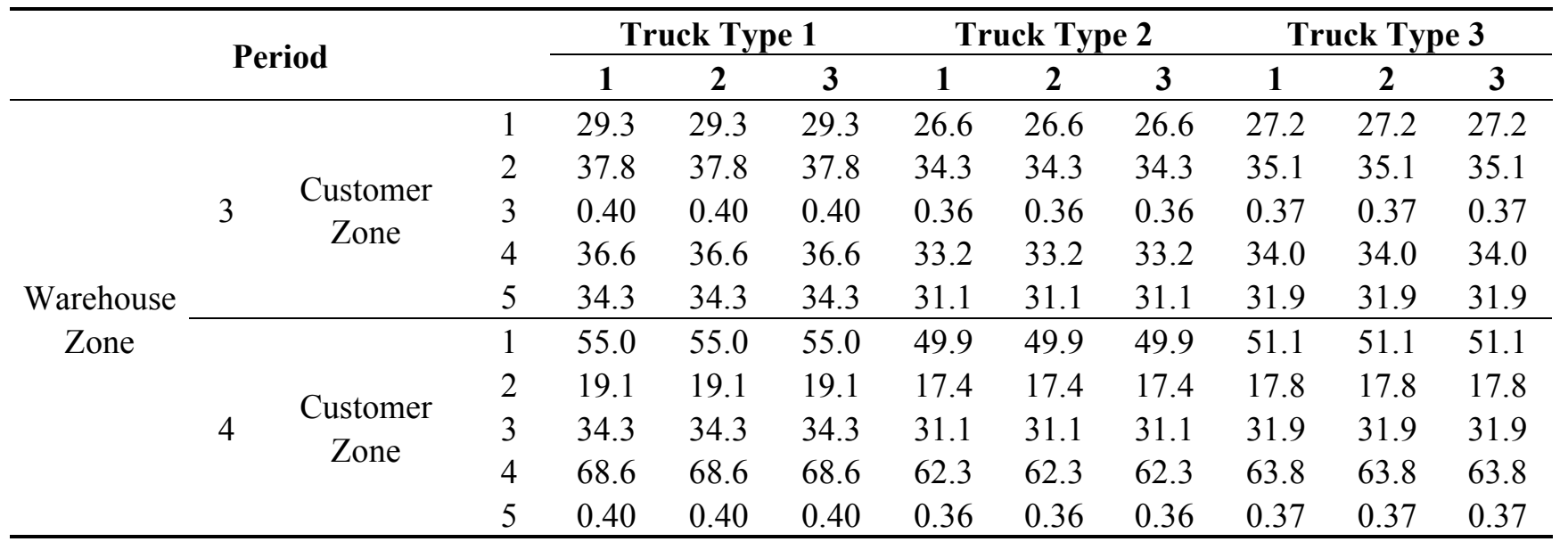

Table 13. Product manufacturing costs (\$/unit) at different periods.

\begin{tabular}{ccccc}
\hline & Manufacturing Zone 1 & Manufacturing Zone 2 & Manufacturing Zone 3 \\
\hline \multirow{3}{*}{ Period } & 1 & 1.35 & 1.23 & 2.60 \\
& 2 & 1.50 & 1.56 & 2.50 \\
& 3 & 1.51 & 1.50 & 2.65 \\
\hline
\end{tabular}

Table 14. Capacities of the suppliers, manufacturing zones and warehouse zones at different periods.

\begin{tabular}{ccccc}
\hline & & Period 1 & Period 2 & Period 3 \\
\hline \multirow{3}{*}{ Supplier } & 1 & 16,500 & 16,000 & 15,500 \\
& 2 & 12,000 & 12,500 & 12,000 \\
\multirow{3}{*}{ Manufacturing zone } & 3 & 11,000 & 12,000 & 11,500 \\
& 1 & 15,200 & 14,500 & 15,000 \\
& 2 & 12,500 & 13,500 & 12,500 \\
Warehouse zone & 3 & 14,500 & 14,000 & 14,500 \\
& 1 & 13,200 & 12,500 & 11,500 \\
& 2 & 10,500 & 13,500 & 12,000 \\
& 3 & 12,000 & 12,000 & 12,500 \\
& 4 & 9000 & 8500 & 8800 \\
\hline
\end{tabular}

Table 15. Demands of the customer zones at different periods.

\begin{tabular}{rrccc}
\hline Demand & & Period 1 & Period 2 & Period 3 \\
\hline & 1 & 8500 & 9000 & 7500 \\
Customer Zone & 2 & 8700 & 8000 & 8500 \\
& 3 & 8600 & 8500 & 8000 \\
& 4 & 5500 & 6000 & 5600 \\
& 5 & 5000 & 5500 & 5000 \\
\hline
\end{tabular}


Table 16. Trucks' capacities at different periods.

\begin{tabular}{ccccc}
\hline & & Period 1 & Period 2 & Period 3 \\
\hline \multirow{3}{*}{ Truck type } & 1 & 7000 & 7000 & 7000 \\
& 2 & 18,000 & 18,000 & 18,000 \\
& 3 & 24,000 & 24,000 & 24,000 \\
\hline
\end{tabular}

The proposed model is solved using LINGO optimization software package developed by LINDO system Inc. to obtain optimal solution, as shown in Table 17. The presented model considered the resilience factor in the supply chain network design, which helps to maintain the sustainability during disruption risks. The analysis of the results shows that the network design depends on the weightage given to each objective; if more importance is given to the total cost goal, then the sustainability of supply chain is reduced and also the vulnerability of the supply chain network increases. This shows that sustainability is parallel to the resilience of the network, that is an increase in the resilience of supply chain network also increases its sustainability. This is due to the fact that during a disruption in networks, firms try to switch their operations from one zone to another, which results in a reduction of sustainability, due to an increase in $\mathrm{CO}_{2}$ emissions and the embodied carbon footprints.

Table 17. Case example solution under different situations.

\begin{tabular}{|c|c|c|}
\hline Optimized Goal Values & $\begin{array}{r}\text { Cost goal }(\mathrm{A}) \\
\text { Carbon emission go } \\
\text { Embodied carbon footprin } \\
\text { Disruption cost go }\end{array}$ & $\begin{array}{l}=\$ 1,983,192.00 \\
\text { al }(B)=19,666.04 \mathrm{~kg}, \\
\text { its goal }(C)=199,590.00 \mathrm{~kg}, \\
\text { al }(D)=\$ 303,712.50\end{array}$ \\
\hline Case I & Case II & Case III \\
\hline$\beta_{1}=0.4, \beta_{2}=0.2, \beta_{3}=0.2, \beta_{4}=0.2$ & $\beta_{1}=0.1, \beta_{2}=0.4, \beta_{3}=0.4, \beta_{4}=0.1$ & $\beta_{1}=0.2, \beta_{2}=0.2, \beta_{3}=0.2, \beta_{4}=0.4$ \\
\hline$d_{a}^{+}=\$ 162,805.00$ & $d_{a}^{+}=\$ 189,725.40$ & $d_{a}^{+}=\$ 236,934.3$ \\
\hline$d_{b}^{+}=179.62 \mathrm{~kg}$ & $d_{b}^{+}=178.77 \mathrm{~kg}$ & $d_{b}^{+}=1718.278 \mathrm{~kg}$ \\
\hline$d_{c}^{+}=12,220.00 \mathrm{~kg}$ & $d_{c}^{+}=0.00 \mathrm{~kg}$ & $d_{c}^{+}=3590.00 \mathrm{~kg}$ \\
\hline$d_{d}^{+}=\$ 244,807.50$ & $d_{d}^{+}=\$ 73,067.00$ & $d_{d}^{+}=\$ 17.50$ \\
\hline $\operatorname{TQSM}_{(1,1,2,1)}=12,000.00$ & $\operatorname{TQSM}_{(1,1,2,1)}=9700.00$ & $\operatorname{TQSM}_{(1,1,2,1)}=16,500.00$ \\
\hline $\operatorname{TQSM}_{(1,1,2,2)}=13,700.00$ & $\operatorname{TQSM}_{(1,1,2,2)}=16,000.00$ & $\operatorname{TQSM}_{(1,1,2,3)}=8500.00$ \\
\hline $\operatorname{TQSM}_{(2,2,1,1)}=7000.00$ & $\operatorname{TQSM}_{(2,2,2,2)}=2000.00$ & $\operatorname{TQSM}_{(2,2,2,3)}=9400.00$ \\
\hline $\operatorname{TQSM}_{(2,2,1,2)}=7000.00$ & $\operatorname{TQSM}_{(2,2,3,1)}=13,300.00$ & $\operatorname{TQSM}_{(2,2,3,1)}=6500.00$ \\
\hline $\operatorname{TQSM}_{(2,2,2,2)}=4300.00$ & $\operatorname{TQSM}_{(2,2,3,2)}=9700.00$ & $\operatorname{TQSM}_{(2,2,3,2)}=4500.00$ \\
\hline $\operatorname{TQSM}_{(2,2,3,1)}=11,000.00$ & $\operatorname{TQSM}_{(2,2,3,3)}=5400.00$ & $\operatorname{TQSM}_{(2,2,3,3)}=5500.00$ \\
\hline $\operatorname{TQSM}_{(2,2,3,2)}=1100.00$ & $\operatorname{TQSM}_{(3,3,2,1)}=8300.00$ & $\operatorname{TQSM}_{(3,3,2,1)}=1500.00$ \\
\hline $\operatorname{TQSM}_{(3,3,1,3)}=7000.00$ & $\operatorname{TQSM}_{(3,3,3,1)}=10,700.00$ & $\operatorname{TQSM}_{(3,3,3,1)}=17,500.00$ \\
\hline $\operatorname{TQSM}_{(3,3,2,1)}=6000.00$ & $\operatorname{TQSM}_{(3,3,3,2)}=14,300.00$ & $\operatorname{TQSM}_{(3,3,3,2)}=19,500.00$ \\
\hline $\operatorname{TQSM}_{(3,3,3,1)}=13,000.00$ & $\operatorname{TQSM}_{(3,3,3,3)}=18,500.00$ & $\operatorname{TQSM}_{(3,3,3,3)}=18,500.00$ \\
\hline $\operatorname{TQSM}_{(3,3,3,2)}=19,500.00$ & $\operatorname{TQMW}_{(1,1,1,1)}=3700.00$ & $\operatorname{TQMW}_{(1,1,3,1)}=11,200.00$ \\
\hline $\operatorname{TQSM}_{(3,3,3,3)}=6300.00$ & $\operatorname{TQMW}_{(1,1,1,2)}=6500.00$ & $\operatorname{TQMW}_{(1,1,3,2)}=10,500.00$ \\
\hline $\operatorname{TQMW}_{(1,1,1,1)}=7000.00$ & $\operatorname{TQMW}_{(1,1,3,1)}=9500.00$ & $\mathrm{TQMW}_{(1,1,3,3)}=3300.00$ \\
\hline $\mathrm{TQMW}_{(1,1,1,2)}=7000.00$ & $\mathrm{TQMW}_{(1,1,3,2)}=6000.00$ & $\operatorname{TQMW}_{(2,3,2,1)}=12,000.00$ \\
\hline $\operatorname{TQMW}_{(1,1,3,1)}=6200.00$ & $\mathrm{TQMW}_{(2,3,2,1)}=12,000.00$ & $\mathrm{TQMW}_{(2,3,2,2)}=12,000.00$ \\
\hline $\mathrm{TQMW}_{(1,1,3,2)}=5500.00$ & $\mathrm{TQMW}_{(2,3,2,2)}=12,000.00$ & $\mathrm{TQMW}_{(2,3,3,3)}=1100.00$ \\
\hline $\mathrm{TQMW}_{(2,3,2,1)}=12,000.00$ & $\mathrm{TQMW}_{(2,3,2,3)}=400.00$ & $\operatorname{TQMW}_{(2,4,2,1)}=300.00$ \\
\hline $\operatorname{TQMW}_{(2,3,2,2)}=12,000.00$ & $\operatorname{TQMW}_{(2,4,2,1)}=1000.00$ & $\mathrm{TQMW}_{(2,4,2,2)}=500.00$ \\
\hline
\end{tabular}


Table 17. Cont.

\begin{tabular}{|c|c|c|}
\hline \multirow{2}{*}{$\begin{array}{c}\text { Optimized Goal Values } \\
\text { Case I }\end{array}$} & \multicolumn{2}{|c|}{$\begin{array}{c}\text { Cost goal }(\mathrm{A})=\$ 1,983,192.00 \\
\text { Carbon emission goal }(\mathrm{B})=\mathbf{1 9 , 6 6 6 . 0 4} \mathrm{kg}, \\
\text { Embodied carbon footprints goal }(\mathrm{C})=199,590.00 \mathrm{~kg} \\
\text { Disruption cost goal }(\mathrm{D})=\$ 303,712.50\end{array}$} \\
\hline & Case II & Case III \\
\hline$\beta_{1}=0.4, \beta_{2}=0.2, \beta_{3}=0.2, \beta_{4}=0.2$ & $\beta_{1}=0.1, \beta_{2}=0.4, \beta_{3}=0.4, \beta_{4}=0.1$ & $\beta_{1}=0.2, \beta_{2}=0.2, \beta_{3}=0.2, \beta_{4}=0.4$ \\
\hline $\mathrm{TQMW}_{(2,3,2,3)}=400.00$ & $\mathrm{TQMW}_{(2,4,2,2)}=5000.00$ & $\mathrm{TQMW}_{(3,2,3,1)}=10,500.00$ \\
\hline $\operatorname{TQMW}_{(2,4,2,1)}=1000.00$ & $\operatorname{TQMW}_{(3,2,2,3)}=12,000.00$ & $\operatorname{TQMW}_{(3,2,3,2)}=13,500.00$ \\
\hline $\mathrm{TQMW}_{(2,4,2,2)}=5000.00$ & $\operatorname{TQMW}_{(3,2,3,1)}=10,500.00$ & $\operatorname{TQMW}_{(3,2,3,3)}=12,000.00$ \\
\hline $\operatorname{TQMW}_{(3,2,2,3)}=12,000.00$ & $\operatorname{TQMW}_{(3,2,3,2)}=13,500.00$ & $\mathrm{TQMW}_{(3,4,2,1)}=5700.00$ \\
\hline $\mathrm{TQMW}_{(3,2,3,1)}=10,500.00$ & $\mathrm{TQMW}_{(3,4,2,1)}=5000.00$ & $\mathrm{TQMW}_{(3,4,2,2)}=5500.00$ \\
\hline $\mathrm{TQMW}_{(3,2,3,2)}=13,500.00$ & TQMW $_{(3,4,2,2)}=1000.00$ & $\operatorname{TQMW}_{(3,4,3,1)}=2300.00$ \\
\hline $\mathrm{TQMW}_{(3,4,2,1)}=5000.00$ & $\operatorname{TQMW}_{(3,4,2,3)}=1300.00$ & $\operatorname{TQMW}_{(3,4,3,3)}=7500.00$ \\
\hline $\mathrm{TQMW}_{(3,4,2,2)}=1000.00$ & $\mathrm{TQMW}_{(3,4,3,1)}=4000.00$ & $\mathrm{TQWC}_{(1,1,2,1)}=8500.00$ \\
\hline $\operatorname{TQMW}_{(3,4,2,3)}=1300.00$ & $\operatorname{TQMW}_{(3,4,3,2)}=4500.00$ & $\mathrm{TQWC}_{(1,1,2,2)}=9000.00$ \\
\hline $\operatorname{TQMW}_{(3,4,3,1)}=4000.00$ & $\mathrm{TQWC}_{(1,1,2,1)}=8500.00$ & $\mathrm{TQWC}_{(1,1,2,3)}=7500.00$ \\
\hline TQMW $_{(3,4,3,2)}=4500.00$ & $\mathrm{TQWC}_{(1,1,2,2)}=9000.00$ & $\mathrm{TQWC}_{(2,2,2,1)}=4000.00$ \\
\hline $\operatorname{TQWC}_{(1,1,2,1)}=8500.00$ & $\operatorname{TQWC}_{(1,1,2,3)}=7500.00$ & $\mathrm{TQWC}_{(2,2,3,1)}=4700.00$ \\
\hline $\mathrm{TQWC}_{(1,1,2,2)}=9000.00$ & $\operatorname{TQWC}_{(1,3,2,1)}=700.00$ & $\mathrm{TQWC}_{(2,2,3,2)}=8000.00$ \\
\hline $\mathrm{TQWC}_{(1,1,2,3)}=7500.00$ & $\mathrm{TQWC}_{(2,2,2,1)}=4000.00$ & $\mathrm{TQWC}_{(2,2,3,3)}=8500.00$ \\
\hline $\mathrm{TQWC}_{(1,3,2,2)}=700.00$ & $\operatorname{TQWC}_{(2,2,3,1)}=4700.00$ & $\mathrm{TQWC}_{(2,4,2,1)}=1800.00$ \\
\hline $\mathrm{TQWC}_{(2,2,2,1)}=4000.00$ & $\mathrm{TQWC}_{(2,2,3,2)}=8000.00$ & $\mathrm{TQWC}_{(2,4,2,2)}=5500.00$ \\
\hline $\mathrm{TQWC}_{(2,2,3,1)}=4700.00$ & $\mathrm{TQWC}_{(2,2,3,3)}=8500.00$ & $\mathrm{TQWC}_{(2,4,2,3)}=3500.00$ \\
\hline $\mathrm{TQWC}_{(2,2,3,2)}=8000.00$ & $\operatorname{TQWC}_{(2,4,2,1)}=1800.00$ & $\mathrm{TQWC}_{(3,3,2,2)}=3000.00$ \\
\hline $\mathrm{TQWC}_{(2,2,3,3)}=8500.00$ & $\mathrm{TQWC}_{(2,4,2,2)}=5500.00$ & $\mathrm{TQWC}_{(3,3,2,3)}=4900.00$ \\
\hline $\mathrm{TQWC}_{(2,4,2,1)}=1800.00$ & $\operatorname{TQWC}_{(2,4,2,3)}=3500.00$ & $\mathrm{TQWC}_{(3,3,3,1)}=8600.00$ \\
\hline $\mathrm{TQWC}_{(2,4,2,2)}=5500.00$ & $\operatorname{TQWC}_{(3,3,2,2)}=3000.00$ & $\mathrm{TQWC}_{(3,3,3,2)}=5500.00$ \\
\hline $\mathrm{TQWC}_{(2,4,2,3)}=3500.00$ & $\mathrm{TQWC}_{(3,3,3,1)}=8600.00$ & $\operatorname{TQWC}_{(3,3,3,3)}=3100.00$ \\
\hline $\mathrm{TQWC}_{(3,3,2,3)}=4900.00$ & $\mathrm{TQWC}_{(3,3,3,2)}=5500.00$ & $\mathrm{TQWC}_{(4,4,2,1)}=3700.00$ \\
\hline $\mathrm{TQWC}_{(3,3,3,1)}=8600.00$ & $\mathrm{TQWC}_{(3,3,3,3)}=7300.00$ & $\mathrm{TQWC}_{(4,4,2,2)}=500.00$ \\
\hline $\mathrm{TQWC}_{(3,3,3,2)}=7800.00$ & $\operatorname{TQWC}_{(4,4,2,1)}=3700.00$ & $\operatorname{TQWC}_{(4,4,2,3)}=2100.00$ \\
\hline $\operatorname{TQWC}_{(3,3,3,3)}=3100.00$ & $\mathrm{TQWC}_{(4,4,2,2)}=500.00$ & $\mathrm{TQWC}_{(4,5,3,1)}=5000.00$ \\
\hline $\operatorname{TQWC}_{(4,4,2,1)}=3700.00$ & $\operatorname{TQWC}_{(4,4,2,3)}=2100.00$ & $\mathrm{TQWC}_{(4,5,3,2)}=5500.00$ \\
\hline $\mathrm{TQWC}_{(4,4,2,2)}=500.00$ & $\mathrm{TQWC}_{(4,5,2,3)}=4200.00$ & $\operatorname{TQWC}_{(4,5,3,3)}=5000.00$ \\
\hline $\mathrm{TQWC}_{(4,4,2,3)}=2100.00$ & $\mathrm{TQWC}_{(4,5,3,1)}=5000.00$ & \\
\hline $\mathrm{TQWC}_{(4,5,2,2)}=2300.00$ & $\mathrm{TQWC}_{(4,5,3,2)}=5500.00$ & \\
\hline $\operatorname{TQWC}_{(4,5,3,1)}=5000.00$ & $\mathrm{TQWC}_{(4,5,3,3)}=800.00$ & \\
\hline $\operatorname{TQWC}_{(4,5,3,2)}=3200.00$ & & \\
\hline $\mathrm{TQWC}_{(4,5,3,3)}=5000.00$ & & \\
\hline
\end{tabular}

The results of Case I show the minimum total cost goal deviation $\left(d_{a}^{+}=\$ 162,805.00\right)$, but other goals are highly deviated from their respective target values. This shows that an economical supply chain network cannot be a resilient and sustainable supply chain. Sensitivity analysis is also carried out to show the behavior of the proposed model. Figure 2 shows the percent increase in deviation of the total cost goal and its impact on the percent of deviation of the other three goals. If more importance is given to 
sustainability, then deviations of carbon emission and embodied carbon foot print goals tend to reduce, whereas this increases the deviation of the total cost goal $\left(d_{a}^{+}=\$ 189,725.40\right)$. Case II also reveals that an increment in the weightage of sustainability goals not only reduces their deviations, but also tends to reduce resilience goal deviation $\left(d_{d}^{+}=\$ 73,067.00\right)$. Sensitivity analysis (see Figures 3 and 4 ) also reveals that the design of a sustainable and resilient supply chain network is less an economical network, but has the ability to achieve sustainability targets while coping with disruption risks. Case III and the sensitivity analysis in Figure 5 show that the percent of increase in the deviation of the resilience goal reduces the percent of deviation of the total cost goal. The analysis of the supply flow shows that products should be produced and transported in small quantities in high risk zones, which will reduce the impact of disruption, but increase the cost of production and transportation. This shows that an economical supply chain not only has poor sustainability, but also is highly vulnerable to disruption risks. The results of the case example reveal that firms can minimize the expected disruption cost with a small increment in the total supply chain cost. The proposed model gives many insights into the managing of sustainable supply chain networks under disruption risks, and the model provides a compromise solution by varying the supply flow between supplier, manufacturing, warehouse and customer zones, to meet different goals, as shown in Table 17.

Figure 2. Sensitivity analysis of $\% d_{b}^{+}, \% d_{c}^{+}$and $\% d_{d}^{+}$with $\% d_{a}^{+}$.

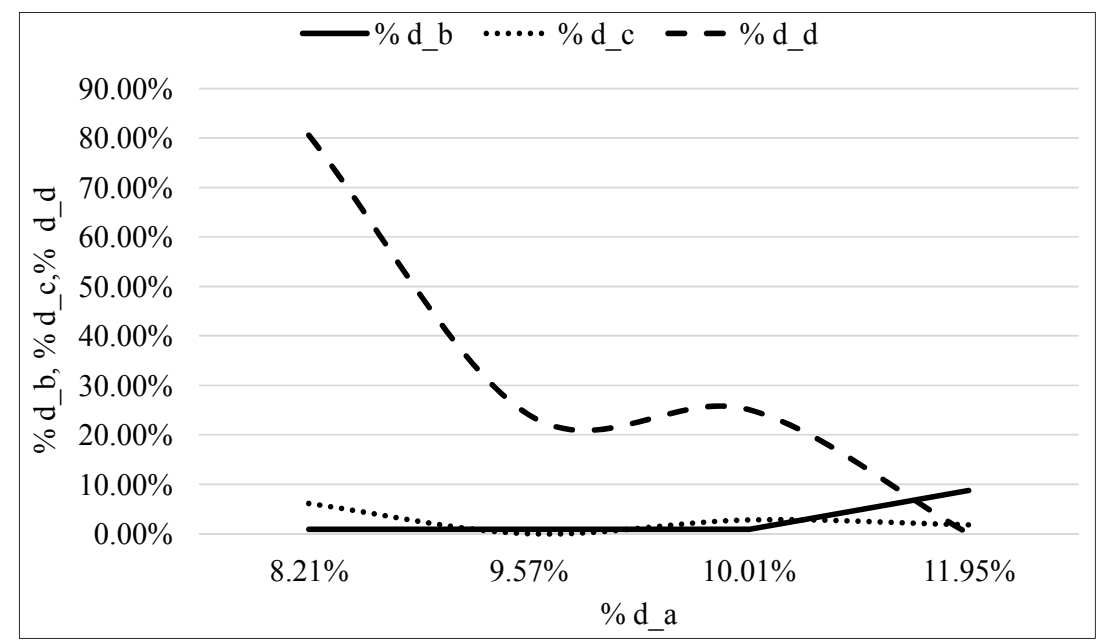

Figure 3. Sensitivity analysis of $\% d_{a}^{+}, \% d_{c}^{+}$and $\% d_{d}^{+}$with $\% d_{b}^{+}$.

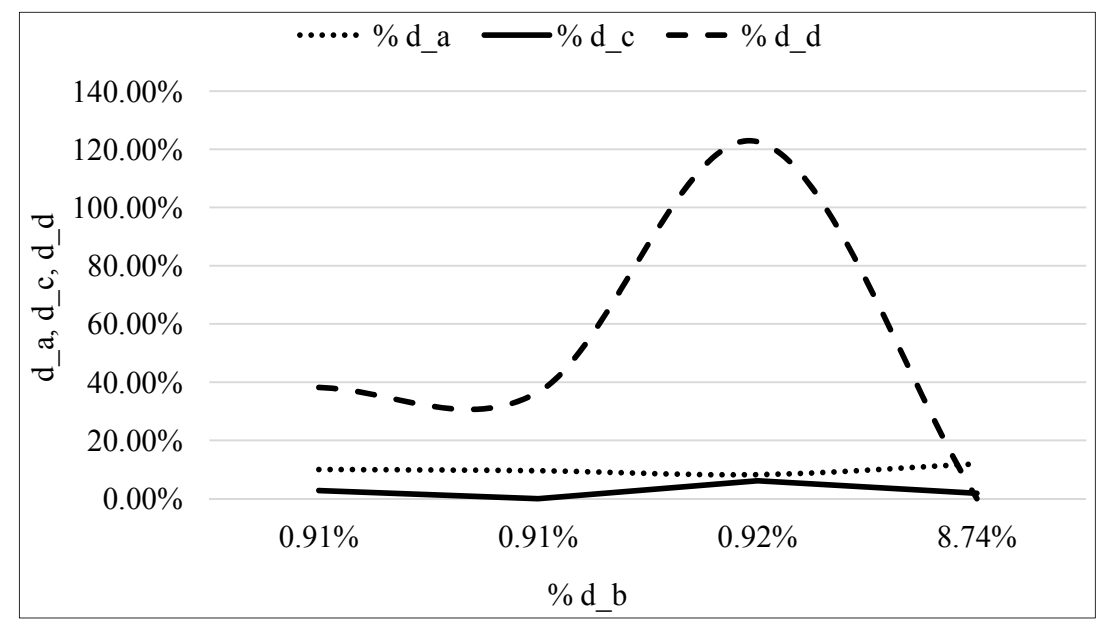


Figure 4. Sensitivity analysis of $\% d_{a}^{+}, \% d_{b}^{+}$and $\% d_{d}^{+}$with $\% d_{c}^{+}$.

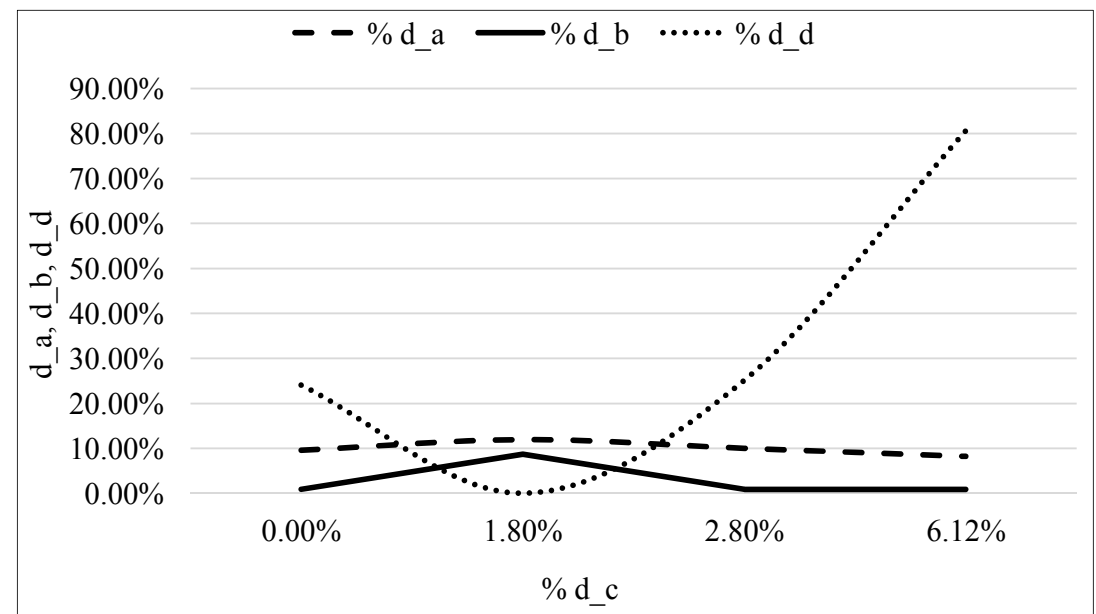

Figure 5. Sensitivity analysis of $\% d_{a}^{+}, \% d_{b}^{+}$and $\% d_{c}^{+}$with $\% d_{d}^{+}$.

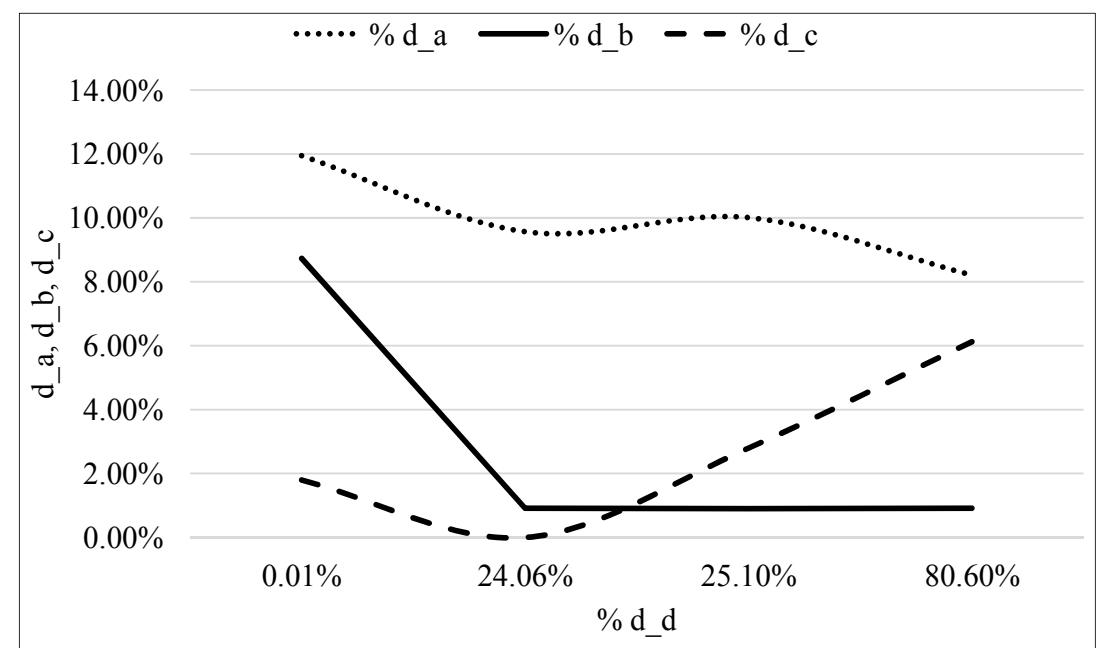

\section{Conclusions}

This paper highlights the importance of supply chain resilience in the design of a sustainable supply chain network. The paper proposed an optimization model for designing a sustainable and resilient supply chain network by incorporating carbon emission and embodied carbon footprints, considering disruption risks. A multi-objective goal programming-based approach is proposed to handle conflicting goals, such as supply chain costs, carbon emissions and disruption costs. The significant contribution of this paper is the inclusion of a resilience factor in the design of the sustainable supply chain network by incorporating location-based risks, because it was observed in practice that maintaining sustainability in a supply chain network is difficult during disruptions, such as natural or manmade disasters.

The proposed model can be extended by incorporating more realistic complexities, such as stochastic demand, multiple products and real-time GIS data, to calculate the probability of disruption risks in various regions. The model can also be extended by incorporating vehicle routing issues in the proposed model, such as the time window, as heavy trucks cannot enter the city during daytime, and road restrictions, for example heavy trucks may not enter some roads. 


\section{Acknowledgments}

This research was supported by the Basic Science Research Program through the National Research Foundation of Korea (NRF) funded by the Ministry of Education, Science and Technology (2012R1A1B3000631).

\section{Author Contributions}

Sonia Irshad Mari developed the concept, mathematical model and drafted the manuscript. Muhammad Saad Memon revised the manuscript and Young Hae Lee supervised the overall work. All authors read and approved the final manuscript.

\section{Conflicts of Interest}

The authors declare no conflict of interest.

\section{References}

1. Kumar Kundu, C. Analysis of Challenges in Existing Textile Retail Business for Implementing Sustainable Resilient Supply Chain; University of Borås: Borås, Sweden, 2010.

2. Beske, P.; Seuring, S. Putting Sustainability into Supply Chain Management. Supply Chain Manag. 2014, 19, 322-331.

3. Elkington, J. Partnerships from cannibals with forks: The triple bottom line of 21 st-century business. Environ. Q. Manag. 1998, 8, 37-51.

4. Amindoust, A.; Ahmed, S.; Saghafinia, A.; Bahreininejad, A. Sustainable supplier selection: A ranking model based on fuzzy inference system. Appl. Soft Comput. 2012, 12, 1668-1677.

5. Choi, T.M. Optimal apparel supplier selection with forecast updates under carbon emission taxation scheme. Comput. Oper. Res. 2013, 40, 2646-2655.

6. Correia, F.; Howard, M.; Hawkins, B.; Pye, A.; Lamming, R. Low carbon procurement: An emerging agenda. J. Purch. Supply Manag. 2013, 19, 58-64.

7. Haake, H.; Seuring, S. Sustainable Procurement of Minor Items-Exploring Limits to Sustainability. Sustain. Dev. 2009, 17, 284-294.

8. Walker, H.; Brammer, S. Sustainable procurement in the United Kingdom public sector. Supply Chain Manag. 2009, 14, 128-137.

9. Nagurney, A.; Liu, Z.G.; Woolley, T. Sustainable Supply Chain and Transportation Networks. Int. J. Sustain. Transp. 2007, 1, 29-51.

10. Sanchez-Rodrigues, V.; Potter, A.; Naim, M.M. The impact of logistics uncertainty on sustainable transport operations. Int. J. Phys. Distr. Logist. 2010, 40, 61-83.

11. Tang, S.; Wang, W.; Cho, S. Reduction Carbon Emissions in Supply Chain Through Logistics Outsourcing. J. Syst. Manag. Sci. 2014, 4, 10-15.

12. Sarkis, J.; Helms, M.M.; Hervani, A.A. Reverse Logistics and Social Sustainability. Corp. Soc. Responsib. Environ. Manag. 2010, 17, 337-354.

13. Linton, J.D.; Klassen, R.; Jayaraman, V. Sustainable supply chains: An introduction. J. Oper. Manag. 2007, 25, 1075-1082. 
14. Paksoy, T. Optimizing a supply chain network with emission trading factor. Sci. Res. Essays 2010, 5, 2535-2546.

15. Schaltegger, S.; Burritt, R.L. Measuring and Managing Sustainability Performance of Supply Chains Review and Sustainability Supply Chain Management Framework. Supply Chain Manag. An Int. J. 2014, 19, 232-241.

16. Shaw, K.; Shankar, R.; Yadav, S.S.; Thakur, L.S. Modeling a low-carbon garment supply chain. Prod. Plan. Control 2013, 24, 851-865.

17. Derissen, S.; Quaas, M.F.; Baumgärtner, S. The relationship between resilience and sustainability of ecological-economic systems. Ecol. Econ. 2011, 70, 1121-1128.

18. Rose, A. Resilience and sustainability in the face of disasters. Environ. Innov. Soc. Transit. 2011, $1,96-100$.

19. Turner, I. Vulnerability and resilience: Coalescing or paralleling approaches for sustainability science? Glob. Environ. Chang. 2010, 20, 570-576.

20. Lebel, L.; Anderies, J.M.; Campbell, B.; Folke, C.; Hatfield-Dodds, S.; Hughes, T.P.; Wilson, J. Governance and the capacity to manage resilience in regional social-ecological systems. Ecol. Econ. 2006, 11, 1-21.

21. Perrings, C. Resilience and sustainable development. Environ. Dev. Econ. 2006, 11, 417-427.

22. Cutter, S.L. Building Disaster Resilience: Steps toward Sustainability. Chall. Sustain. 2013, 1, $72-79$.

23. De Rosa, V.; Gebhard, M.; Hartmann, E.; Wollenweber, J. Robust sustainable bi-directional logistics network design under uncertainty. Int. J. Prod. Econ. 2013, 145, 184-198.

24. Carvalho, H.; Azevedo, S. Trade-offs among lean, agile, resilient and green paradigms in supply chain management: A case study approach. In Proceedings of the Seventh International Conference on Management Science and Engineering Management; Springer: Berlin/Heidelberg, Germany, 2014; pp. 953-968.

25. Btandon-Jones, E.; Squire, B.; Autry, C.; Petersen, K.J. A Contingent Resource-Based Perspective of Supply Chain Resilience and Robustness. J. Supply Chain Manag. 2014, 50, 55-73.

26. Christopher, M.; Peck, H. Building the Resilient Supply Chain. Int. J. Logist. Manag. 2004, 15, $1-14$.

27. Kristianto, Y.; Gunasekaran, A.; Helo, P.; Hao, Y. A model of resilient supply chain network design: A two-stage programming with fuzzy shortest path. Expert Syst. Appl. 2014, 41, 39-49.

28. Pettit, T.J. Supply Chain Resilience: Development of a Conceptual Framework, an Assessment Tool and an Implementation Process. Ph.D. Thesis, The Ohio State University, Columbus, OH, USA, 2008.

29. Pettit, T.J.; Fiksel, J.; Croxton, K.L. Ensuring supply chain resilience: Development of a conceptual framework. J. Bus. Logist. 2010, 31, 1-21.

30. Sheffi, Y.; Closs, D.J.; Davidson, J.; French, D.; Gordon, B.; Martichenko, R.; Mentzer, J.T.; Norek, C.; Seiersen, N.; Stank, T. Supply Chain Resilience. Off. Mag. Logist. Inst. 2006, 12, 1-32.

31. Shukla, A.; Lalit, V.A.; Venkatasubramanian, V. Optimizing efficiency-robustness trade-offs in supply chain design under uncertainty due to disruptions. Int. J. Phys. Distr. Logist. 2011, 41, 623-647. 
32. Azevedo, S.G.; Govindan, K.; Carvalho, H.; Cruz-Machado, V. Ecosilient Index to assess the greenness and resilience of the upstream automotive supply chain. J. Clean. Prod. 2013, 56, 131-146.

33. Chang, C.T. Efficient structures of achievement functions for goal programming models. Asia Pac. J. Oper. Res. 2007, 24, 755-764.

34. Lim, M.K.; Bassamboo, A.; Chopra, S.; Daskin, M.S. Facility location decisions with random disruptions and imperfect estimation. Manuf. Serv. Oper. Manag. 2013, 15, 239-249.

35. Chopra, S.; Sodhi, M.S. Reducing the Risk of Supply Chain Disruptions. MIT Sloan Manag. Rev. 2014, 55, 72-80.

36. Klibi, W.; Martel, A.; Guitouni, A. The design of robust value-creating supply chain networks: A critical review. Eur. J. Oper. Res. 2010, 203, 283-293.

(C) 2014 by the authors; licensee MDPI, Basel, Switzerland. This article is an open access article distributed under the terms and conditions of the Creative Commons Attribution license (http://creativecommons.org/licenses/by/4.0/) 